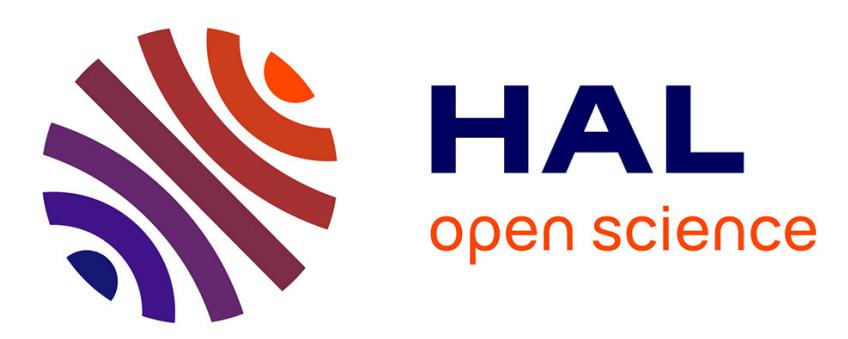

\title{
Effect of substrate on the adsorption of polyelectrolyte multilayers: study by optical fixed-angle reflectometry and AFM
}

C.C. Buron, C. Filiâtre, F. Membrey, C. Bainier, D. Charraut, A. Foissy

\section{To cite this version:}

C.C. Buron, C. Filiâtre, F. Membrey, C. Bainier, D. Charraut, et al.. Effect of substrate on the adsorption of polyelectrolyte multilayers: study by optical fixed-angle reflectometry and AFM. Colloids and Surfaces A: Physicochemical and Engineering Aspects, 2007, 305 (1-3), pp.105-111. 10.1016/j.colsurfa.2007.04.048 . hal-00218170

\section{HAL Id: hal-00218170 \\ https://hal.science/hal-00218170}

Submitted on 18 Apr 2021

HAL is a multi-disciplinary open access archive for the deposit and dissemination of scientific research documents, whether they are published or not. The documents may come from teaching and research institutions in France or abroad, or from public or private research centers.
L'archive ouverte pluridisciplinaire $\mathbf{H A L}$, est destinée au dépôt et à la diffusion de documents scientifiques de niveau recherche, publiés ou non, émanant des établissements d'enseignement et de recherche français ou étrangers, des laboratoires publics ou privés. 


\title{
Effect of substrate on the adsorption of polyelectrolyte multilayers: Study by optical fixed-angle reflectometry and AFM
}

\author{
C.C. Buron ${ }^{\mathrm{a}}$, C. Filiâtre ${ }^{\mathrm{a}, *}$, F. Membrey ${ }^{\mathrm{a}}$, C. Bainier ${ }^{\mathrm{b}}$, D. Charraut ${ }^{\mathrm{b}}$, A. Foissy ${ }^{\mathrm{a}}$ \\ a Institut Utinam-UMR 6213, Université de Franche-Comté, Besançon, France \\ b FEMTO-ST, Département d'Optique LOPMD, CNRS/Université de Franche-Comté, Besançon, France
}

\begin{abstract}
Self-assembled multilayer films were formed on several chemically modified silica substrates: bare silica, aminated silica and two hydrophobically modified silicas prepared by grafting octadecyl (ODS) and propyl (PMS) trimethoxysilanes. The polyelectrolytes were poly(trimethylammonium ethyl methacrylate chloride) (MADQUAT) and poly(acrylic acid) (PAA). Analysis of the polyelectrolyte uptake was made with optical fixed-angle reflectometry and the film morphology was imaged with atomic force microscopy (AFM). All experiments were made at $20^{\circ} \mathrm{C}$ and $\mathrm{pH} 5.5$ in $\mathrm{NaCl}$ solutions $10^{-3} \mathrm{M}$. On all substrates the growth was not linear in the range of the first five bilayers. There was a very strong dependence of the growth on the functionality of the substrate, which was shown both by the reflectometric output (mass uptake) and by 2D AFM images (heterogeneity). With the unmodified silica substrate the growth was continued up to 20 bilayers, showing a progressive filling of holes and thus smoothing of the polyelectrolyte layer. A patterned substrate was used to demonstrate that two of the different morphologies above could be reproduced and grown on one single sample.
\end{abstract}

Keywords: Polyelectrolyte; Multilayer; Adsorption; Reflectometry; AFM

\section{Introduction}

Since it was first described by Decher and Hong [1] the self-assembly of polyelectrolyte films has known an enthusiastic research development. Some review papers and a book should help to have an overview of the present knowledge in the subject [2-5]. Although there has been a considerable work accomplished, it is amazing how the growth mechanism and the intimate structure of these films remain intensely debated in research articles. For a number of polyelectrolyte pairs a large amount of experimental investigations may be found on the influence of the physico-chemical variables $(\mathrm{pH}$, salt type and concentration, molar mass, etc.) and the process parameters, but because of the wide types of polymer pairs and experimental conditions, one is far from the description of a general model for the construction of films and a guideline to the confection of designed multilayer materials.

\footnotetext{
* Corresponding author. Tel.: +33 381666531 .

E-mail address: claudine.filiatre@univ-fcomte.fr (C. Filiâtre).
}

A particular phenomenon worth careful attention is the influence of the substrate in the first steps of the film construction. An interesting example was given by the influence of a preliminary adsorbed layer of poly(ethylene imine) on the further growth of films made of a large variety of polyelectrolyte pairs [6-8].

A deeper examination of the film properties in the early steps of the growth is also of interest for the application of polyelectrolyte films in the encapsulation of micro- and nano-particles, the core of which might be of any kind, comprising polymer or inorganic solids, emulsified liquids, etc. $[9,10]$. It is easily understandable that changing the core for a given set of polyelectrolytes may have a strong influence onto the elaboration and the properties of the film, since a difference in the very first adsorption steps, due to a different substrate, may have significant repercussions in further steps, up to unknown growth levels.

Aiming to better understand the mechanism involved in the first deposition steps of the polymers, and to probe the consequence of the substrate properties, we have analysed the dependence of the early growth (five bilayers) of selfassembled multilayer films on several chemically modified 
silica substrates used as model substrates (negatively or positively charged, and hydrophobic substrates). Polyelectrolytes are the quaternary ammonium derivative poly(trimethylammonium ethyl methacrylate chloride) (MADQUAT) and the anionic poly(acrylic acid) (PAA).

Differences in the growth were analysed by optical fixedangle reflectometry, which has the advantage to allow fast in situ comparisons of polyelectrolyte uptake, although it does not give unambiguously the adsorbed mass [11]. The morphology of the deposited films was investigated by atomic force microscopy (AFM) after drying.

\section{Materials and techniques}

\subsection{Polyelectrolytes}

MADQUAT, i.e. poly(trimethylammonium ethyl methacrylate chloride) and PAA, i.e. poly(acrylic acid), were kindly supplied by COATEX (Genay, France). MADQUAT had a molar mass $30,000 \mathrm{Da}$, the refractive index increment was $0.185 \mathrm{~mL} \mathrm{~g}^{-1} \quad(\lambda=589.3 \mathrm{~nm})$. It was used as received. PAA had a molar mass $10,000 \mathrm{Da}$ and a refractive index increment $0.210 \mathrm{~mL} \mathrm{~g}^{-1}$. The $\mathrm{p} K_{0.5}$ of PAA (half ionization) was 6.9 in $\mathrm{NaCl} 10^{-3} \mathrm{M}$ [12]. A $10 \%$ hydrophobically modified PAA (DV 883) was also used in one set of experiments. The polyelectrolytes were used in solutions $0.01 \mathrm{~g} \mathrm{~L}^{-1}$ prepared in deionized water with resistivity above $18.2 \mathrm{M} \Omega \mathrm{cm}$. The $\mathrm{pH}$ was adjusted by addition of $\mathrm{HCl}$ and change of ionic strength with $\mathrm{NaCl}$.

\subsection{Substrate and modifications}

Substrate samples were prepared from a silicon wafer (ACM, France) first oxidized by thermal treatment at $1000^{\circ} \mathrm{C}$ for one hour and further cleaned in a piranha solution, rinsed with deionized water and dried in a nitrogen stream. The treatment produced a silica thickness $100 \pm 0.5 \mathrm{~nm}$ (ellipsometric measurement) with a surface completely hydrolysed in the form of $\mathrm{SiOH}$ groups [13]. The contact angle of the generic silica substrate was $0^{\circ}$ (measurement with a goniometer Digidrop, GBX, France). A positive silica substrate was prepared by aminosilane treatment as follows: $12 \mathrm{~h}$ immersion in an ethanol solution containing $1 \mathrm{mmol} \mathrm{L}^{-1} \mathrm{~N}$-6-aminohexyl, aminopropyltrimethoxysilane [14-16] leading to a grafted amino groups density of about 2 sites $/ \mathrm{nm}^{2}$ at $\mathrm{pH} 5.5$ [12]. However silanation reaction does not consume all the initial silanol groups produced by the cleaning treatment. Substrate becomes a bipolar surface with a possibility of ratio charge $\left(\left[\mathrm{R}-\mathrm{NH}_{3}{ }^{+}\right] /\left[\mathrm{SiO}^{-}\right]\right)$ modulation using variation of $\mathrm{pH}$. Hydrophobically modified substrates were prepared by chemical vapor deposition using two kinds of alkylsilane: octadecyltrimethoxysilane (ODS) and propyltrimethoxysilane (PMS). The cleaned silica substrate was placed with $0.2 \mathrm{~cm}^{3}$ of liquid alkylsilane in a vessel that was further sealed and heated $3 \mathrm{~h}$ in an oven at $150{ }^{\circ} \mathrm{C}$ [17]. The excess of ungrafted silanes was removed by ultrasonication for 2 min in ethanol for the aminated group and in heptane for the alkyl derivatives. The contact angles of ODS and PMS with water were $108^{\circ}$ and $78^{\circ}$, respectively.
A micropattern surface with silica and a masking resin was prepared by contact photolithography using a photoresist (Shipley 1813). The photoresist was deposited by spin coating (4000 rpm, $30 \mathrm{~s}$ ) before a soft back of $2 \mathrm{~min}$ at $120^{\circ} \mathrm{C}$. The wafer was then irradiated with a UV-light beam $\left(60 \mathrm{~mJ} \mathrm{~cm}^{-2}\right.$, $1 \mathrm{~min}$ ) through a mask, developed in a solution of AZ-726 during $30 \mathrm{~s}$ and finally washed with water. ODS was further grafted on the apparent silica surface. The resin was eventually washed out in acetone. The patterned presented squares of size $50 \mu \mathrm{m} \times 50 \mu \mathrm{m}$.

\subsection{Optical fixed-angle reflectometry}

Optical reflectometry has become a widely spread in situ investigation technique for measuring the change of refractive index in a solid-liquid interface, i.e. to measure the adsorption of a polyelectrolyte on a substrate. In the simplest case the technique gives access to the surface excess of a polyelectrolyte through the relation:

$$
\frac{S-S_{0}}{S_{0}}=A_{\mathrm{s}} \Gamma
$$

where $S$ or $S_{0}$ is the ratio of the parallel and perpendicular components of the reflected intensity of the polarized incident beam ( $\left.S=R_{\mathrm{p}} / R_{\mathrm{S}}\right) . S_{0}$ and $S$ are the ratios measured before and after adsorption of a polyelectrolyte layer. $A_{\mathrm{s}}$ is the sensitivity factor. It has been shown that the relation above, with a constant $A_{\mathrm{s}}$ value, strictly applies in the case of a single polyelectrolyte layer. The reason for that and the ways to sort out the polyelectrolyte uptake from the reflectometric signal in the case of multilayer adsorption may be found elsewhere [18]. In the present investigation we shall only use the change of the output $\left(\Delta S / S_{0}\right)$ upon introduction of the polyelectrolyte solutions, in a relative way, which will carry no quantitative ambiguity in the comments and discussions.

The home-made instrument was described previously [19]. Shortly, it is composed of a prismatic cell with an inlet capillary that produces a flow with a stagnation point, where the laser beam hits the substrate. Therefore, at this point the polyelectrolyte is transported to the adsorption site by simple diffusion. All experiments were carried out at $20^{\circ} \mathrm{C}, \mathrm{pH} 5.5$ and constant ionic strength $10^{-3} \mathrm{M}$. The polyelectrolyte solutions were prepared the day before the experiment. The polymer solution was injected during $10 \mathrm{~min}$ which was found largely in excess of the time to reach a plateau (about 10s). Former investigations have shown that the polymer concentration and the flow rate had a strong influence in the adsorption rate, due to the diffusionconvection determining step, and sometimes in the plateau level [20]. The dependence of the adsorption density at the plateau is generally attributed to the polymer size distribution of the sample, the larger the polydispersity (or the polymer size) the larger the adsorption. In the present case the experiments were repeated three times and the overall uncertainty in the output signal was below $10 \%$. Ten alternate deposits of MADQUAT and PAA (or reverse) were made, i.e. five bilayers. There has been no rinsing between two polyelectrolyte solutions. Indeed rinsing after polymer deposition, using a solution at the same 
$\mathrm{pH}$ and ionic strength did not cause any change neither of the output of the reflectometer nor of the final AFM pictures.

\subsection{Atomic force microscopy}

The AFM microscope (NT-MDT with a SMENA measuring head) is well fitted to the analysis of surface topography. The probe had a curvature about $10 \mathrm{~nm}$, a $10-20 \mathrm{~mm}$ tip height, cone angle less than $22^{\circ}$. The resonant frequency of the cantilever was $255 \mathrm{kHz}$. The microscope was used in tapping (semi contact) mode.

\section{Results and discussion}

\subsection{Adsorption on negatively charged substrate}

First, the two polyelectrolytes were deposited alternately, step by step on the generic silica substrate. A typical recording of the reflectometric output is shown in Fig. 1. Under the assumption that the output signal is nearly proportional to the mass uptake, we see that the deposit increases regularly at each step and clearly more so with the cationic (plus sign) than the anionic polyelectrolyte. An exponential function was found to fit satisfactorily with the whole curve $\left(\Delta S / S_{0}=c \exp (b n), n\right.$ is the number of steps). Naturally, in the former experiment the first polyelectrolyte was MADQUAT since the silica surface was charged negatively. An exponential growth was reported many times in the literature [21-24]. It has been explained by the capacity of one of the polyelectrolyte to diffuse inward and outward within the layer at each change of feed solution [7,24]. The exponential growth may be also explained by a significant and progressive increase of the film roughness [2]. Note the growth may be linear (i.e. increase of the same amount at each step) in some cases, apparently this occurred when the polyelectrolytes were highly charged, forming nice superposed thin layers [25].

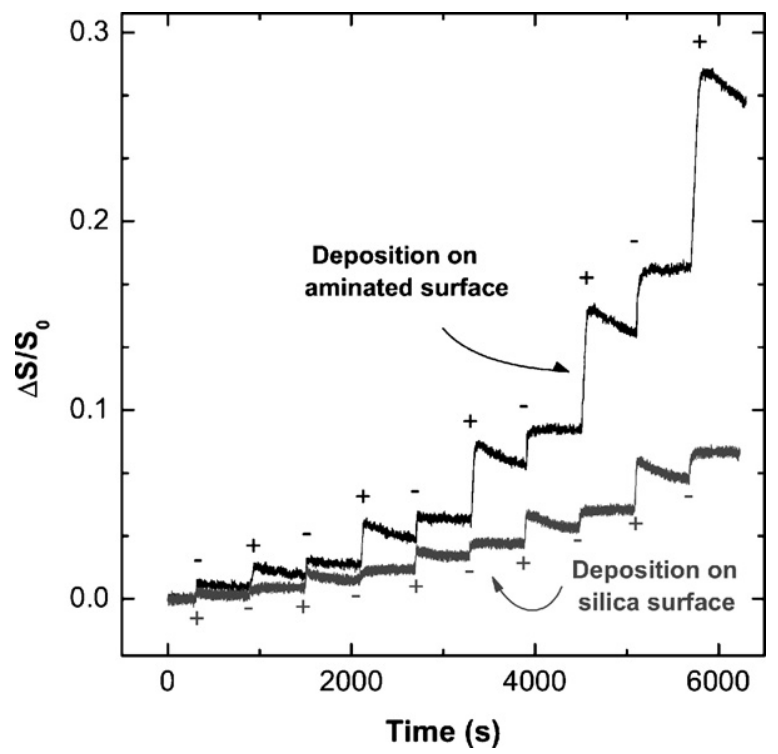

Fig. 1. Evolution of the reflectometric signal $\Delta S / S_{0}$ vs. time during the multilayer adsorption (five bilayers) on silica surface (MADQUAT was first introduced) and on aminated surface (PAA was first introduced).

\subsection{Adsorption on positively charged substrate}

Deposition on the aminosilane modified substrate started with PAA since the surface was positive. In this case the five bilayer film delivered an output about five times that on bare silica (Fig. 1), which means about five more polyelectrolyte uptake. The difference is attributed to the much higher charge density of the aminated surface in comparison with the charge density of bare silica, which allowed a much higher adsorption of PAA than MADQUAT in the former case. At this point it is useful to recall that the adsorption of a polyelectrolyte is largely determined by the opposite charge density of the substrate. When no other specific bonds are present, the adsorption of a polyelectrolyte is more or less limited at the level of charge compensation of the surface [26]. Naturally, the same principle may apply when a polyelectrolyte binds with a formerly deposited polyelectrolyte of opposite charge. At the second step the cationic polyelectrolyte may adsorb both on the former deposited PAA molecules and also on the $\mathrm{SiO}^{-}$sites of the silica surface areas which were not grafted by the aminosilanes. The higher adsorption of the first polyelectrolyte bilayer induced the higher uptakes in subsequent steps.

\subsection{Adsorption on hydrophobic substrates}

In the case of hydrophobically modified surfaces we saw no adsorption of polyelectrolytes on PMS but there was some on ODS for MADQUAT and further steps (Fig. 2). In the case of ODS, Hozumi et al. [17] reported the measurement of a negative streaming potential, which was attributed to the loose packing of the long hydrophobic tails. We infer that some MADQUAT molecules found a path through the hydrophobic film and bound onto uncovered silica patches. Concerning the difference between ODS and PMS, we are lead to think that PMS formed a tighter packing. The influence of the pro-

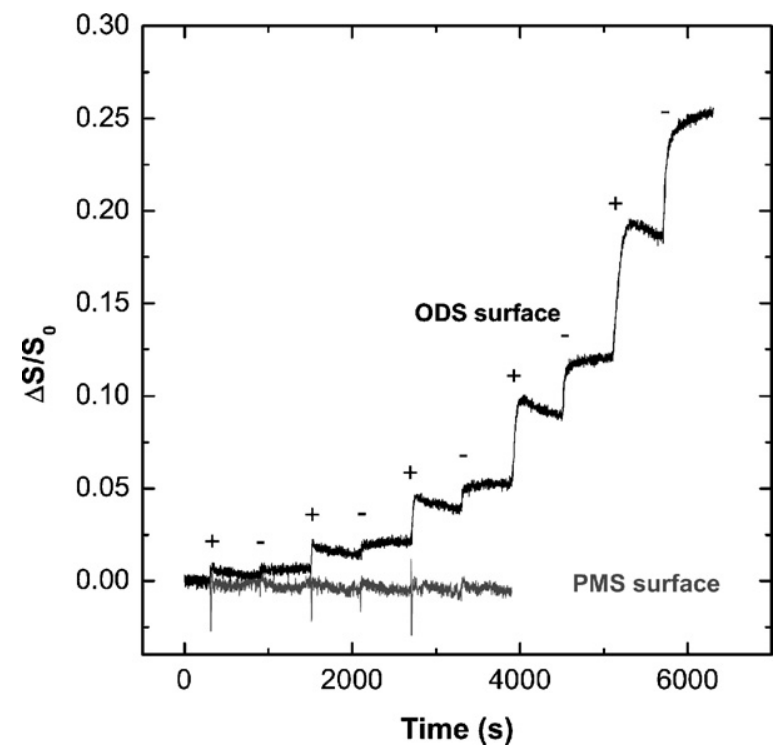

Fig. 2. Evolution of the reflectometric signal $\Delta S / S_{0}$ vs. time during the multilayer adsorption on PMS and ODS surfaces (the first polyelectrolyte is MADQUAT) 


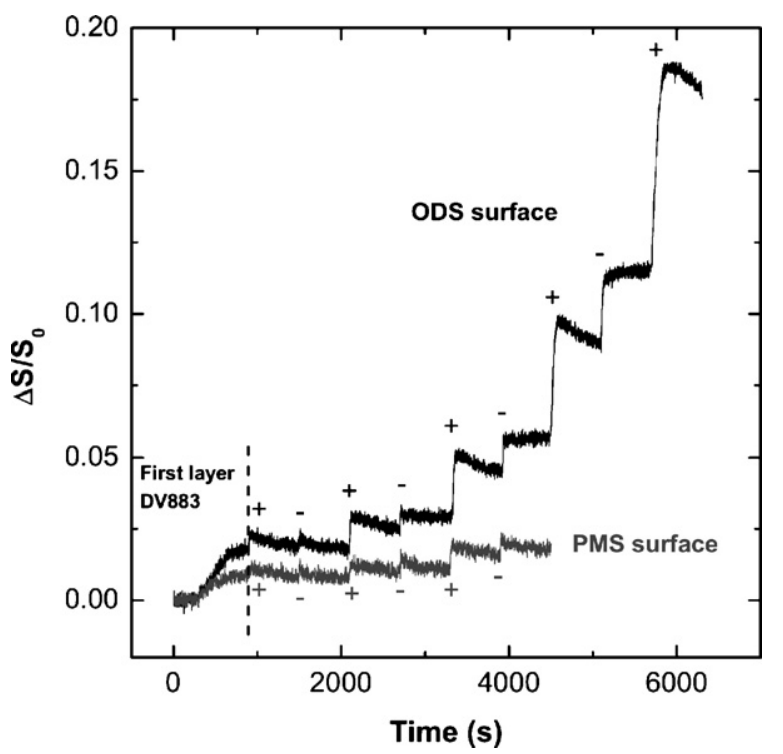

Fig. 3. Evolution of the reflectometric signal $\Delta S / S_{0}$ vs. time during the multilayer adsorption on PMS and ODS surfaces when the first layer is an hydrophobically modified polyanion (DV 883).

cess parameter and the type of alkylsilane on the morphology of the self-assembly of grafted molecules are very complex [13]. It should deserve more attention in further work of this kind.

Since the modified surface was largely hydrophobic we also used a hydrophobically modified anionic polyelectrolyte (DV 883), to start the deposition series on PMS and ODS. As seen in Fig. 3, the relative variation of the reflectometric signal on ODS was higher than on PMS. We explain the difference as follows. The adsorption of DV 883 was probably similar on ODS and PMS, since (i) the binding was due to the hydrophobic interaction and (ii) the limit for adsorption was, as it is generally the case, the kinetic barrier raised between the charge excess of the deposited film and the incoming macromolecules [11]. In the second step, MADQUAT could bind with the deposited DV 883 but it could also bind with the remaining bare silica surface (through the hydrophobic alkyl layer, as explained above) in the case of ODS, which explains the higher surface coverage in comparison with the impenetrable PMS layer.

\subsection{Overshoots during cationic polyelectrolyte adsorption}

We can also notice on figures that the adsorption of MADQUAT exhibited overshoots in the reflectometric signals at $\mathrm{pH} 5.5$ for the different modified substrates. Overshoots, which are an occasional feature of reflectometric measurements, were discussed in several papers. Experiments performed by Kovacevic et al. [11] revealed the further dissolution of polymer complexes formed during an early stage of adsorption. Another explanation was based on the rearrangement of the polyelectrolytes in the adsorbed layer [27]. Additional experiments had been carried out in order to understand the reason of the overshoot in our experimental conditions and this feature will be discussed in an incoming paper.

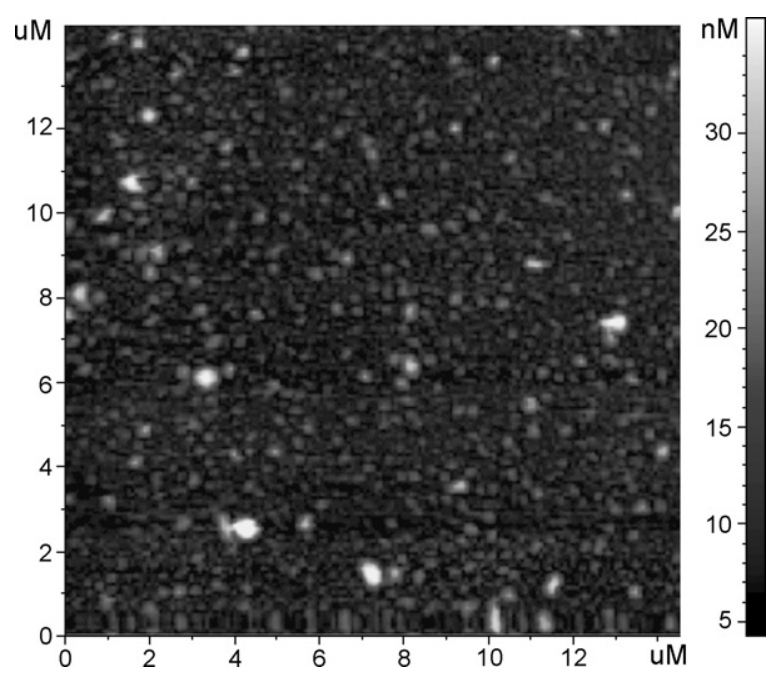

Fig. 4. Two-dimensional AFM image of the multilayer (five MADQUAT/PAA bilayers) deposited on silica surface.

\subsection{Surface morphology}

AFM pictures of the dried polyelectrolyte films (five bilayers unless stated otherwise) were made for the different substrates. The films on silica (Fig. 4) revealed peaks (white spots) less than $1 \mu \mathrm{m}$ size and a roughness (average difference between peaks and valleys) in the range $20-30 \mathrm{~nm}$. It is not known whether the valleys around the peaks reached the silica surface or a continuous polyelectrolyte film. The progressive aspect of the film topography when growing up to 20 bilayers is shown in Fig. 5. We see that the peaks become much wider (10 bilayers) and the films smooth over from filling the holes, but a few cavities remain. Similar pictures by Picart et al. [6] showed a progressive transition from an island like structure to an uniform film after six bilayers with the pair poly(L-lysine)-hyaluronic acid on glass. In comparison the films formed on aminated silica showed significantly larger polyelectrolyte heights in the first five bilayers, looking more like tortuous hills (end to end of the order of $4 \mu \mathrm{m}$ ) than peaks (Fig. 6). Due to the larger uptake (Fig. 1) it seems that the five bilayer film on the aminated surface resembles the 10 bilayers on silica (Fig. 5). It is understandable that the film morphology depends considerably on the deposited weight, more so than on the number of steps. This is the reason why we found in another work that AFM images of five bilayers of MADQUAT-PAA deposited in the presence of $10^{-3} \mathrm{M}$ barium chloride (barium enhances significantly the uptake) looked like the 10 bilayers with $\mathrm{NaCl}$ in Fig. 5 [12].

ODS modified surfaces produce films with a large number of isolated fine peaks of diameter about $0.2 \mu \mathrm{m}$ (Fig. 7). The roughness (not shown) was twice that on silica or aminated silica. When using DV 883 as a first layer (Fig. 8) the number of peaks decreased significantly, they were wider (about $2 \mu \mathrm{m}$ ) and higher (some above $300 \mathrm{~nm}$ ). Be aware of the different $z$ scales in Figs. 7 and 8. We explain the particular film morphology on the ODS layer (thin and numerous peaks) as the consequence of the start of the growth, where the first stroke of MADQUAT molecules was more or less pinned through the alkyl layer 


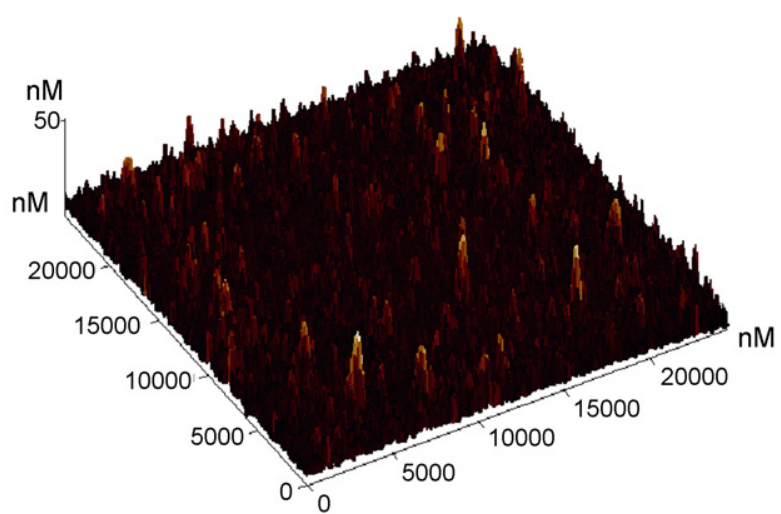

5 bilayers

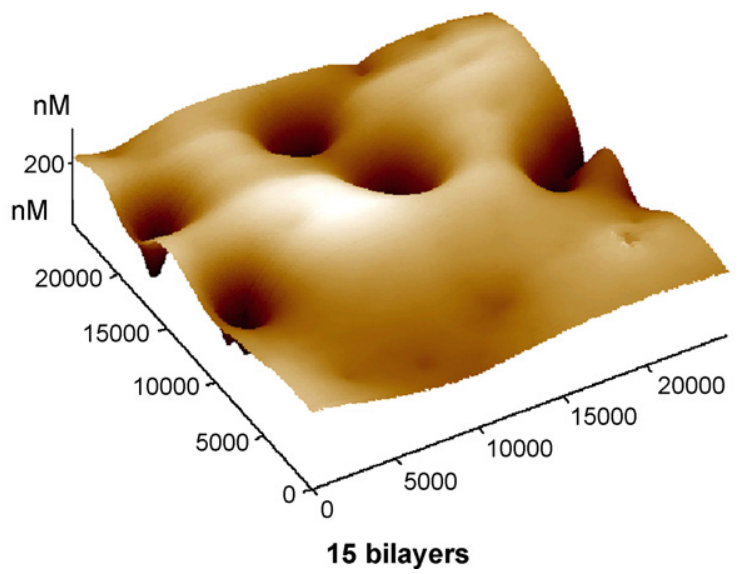

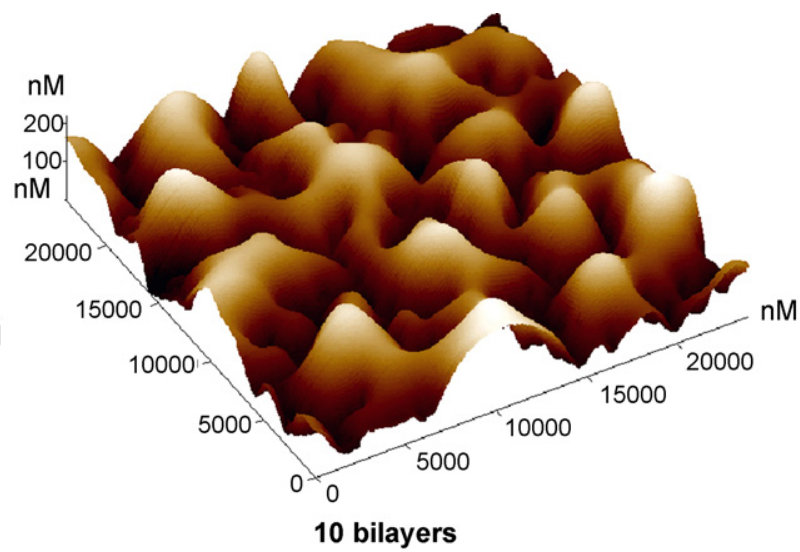

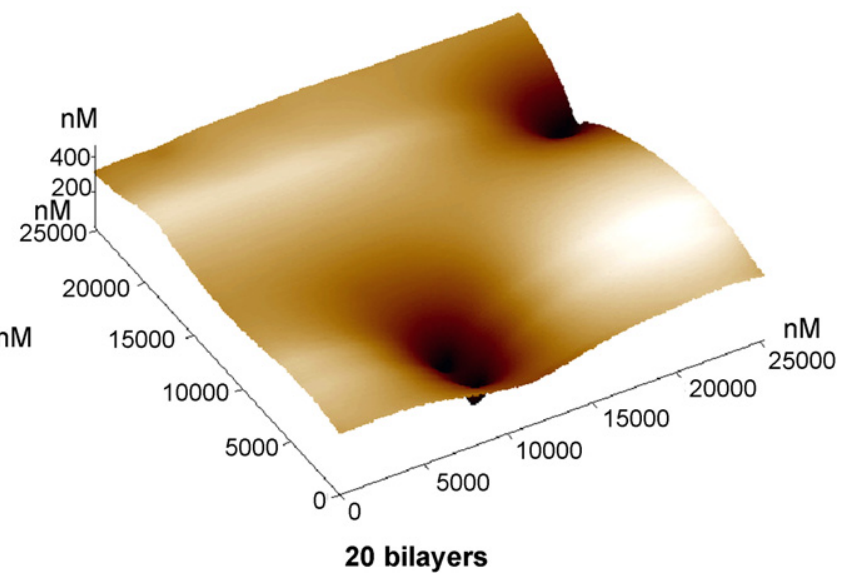

20 bilayers

Fig. 5. Evolution of the surface morphology (AFM images) in function of the number of deposited bilayers.

onto the substrate. These molecules formed a dense distribution of discrete sites for the attachment of PAA molecules. The MADQUAT-PAA macromolecular complexes served as the nuclei for further growth that was essentially orthogonal to the surface.

Alternate MADQUAT-PAA multilayers (10 bilayers) deposited on the silica/ODS micropattern (Fig. 9a and b) pro-

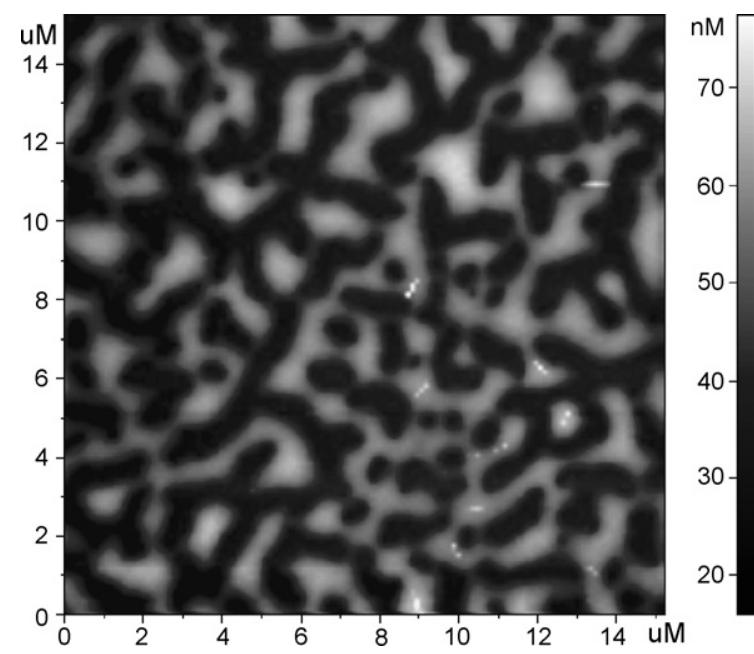

Fig. 6. Two-dimensional AFM image of the multiplayer (five PAA/MADQUAT bilayers) deposited on aminosilane surface. duced an image which is compatible with the results described above. As expected the multilayer on ODS modified squares exhibited a higher roughness and a denser distribution of thin peaks in comparison with the ones on bare silica areas. This picture summarizes nicely the repeatability of the experiments and the influence of the initial state of the substrate in the growth of polyelectrolyte multilayers.

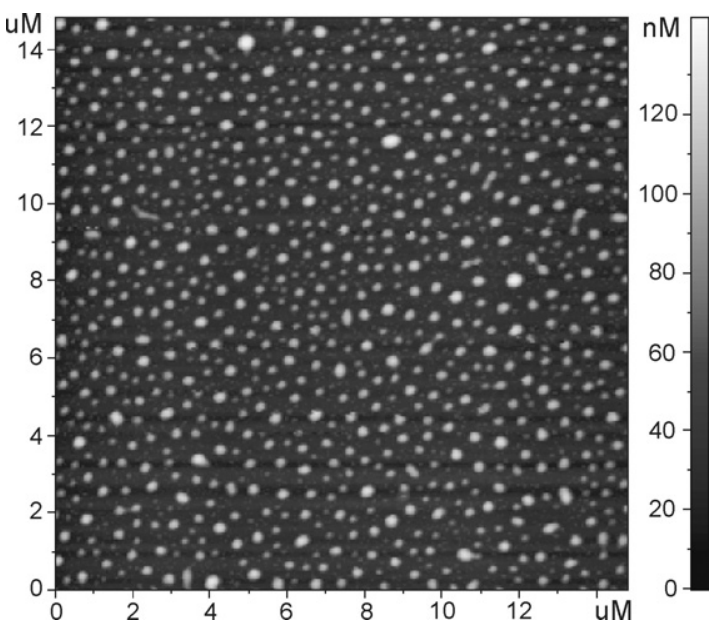

Fig. 7. Two-dimensional AFM image of the multiplayer (five MADQUAT/PAA bilayers) deposited on ODS surface. 


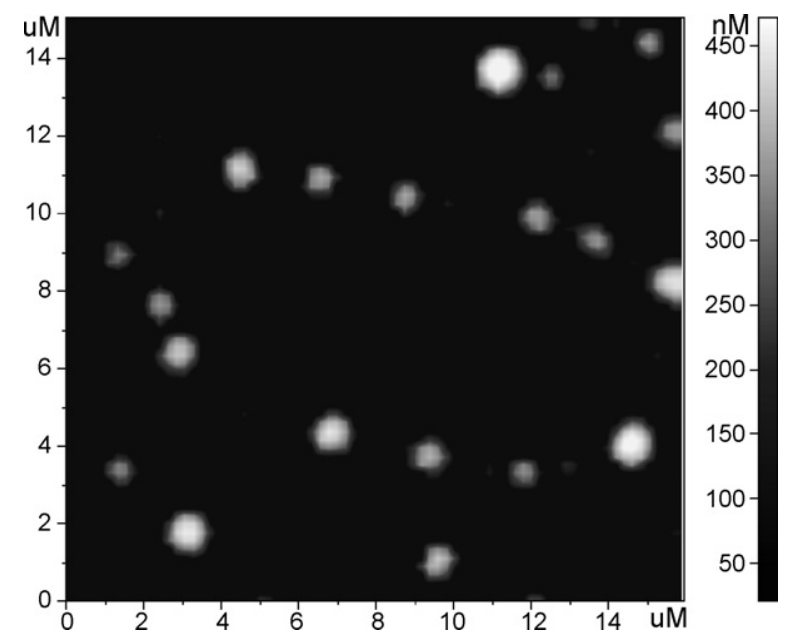

Fig. 8. Two-dimensional AFM image of the multiplayer (five MADQUAT/PAA bilayers) deposited on ODS surface when the first layer is an hydrophobically modified polyanion (DV883).
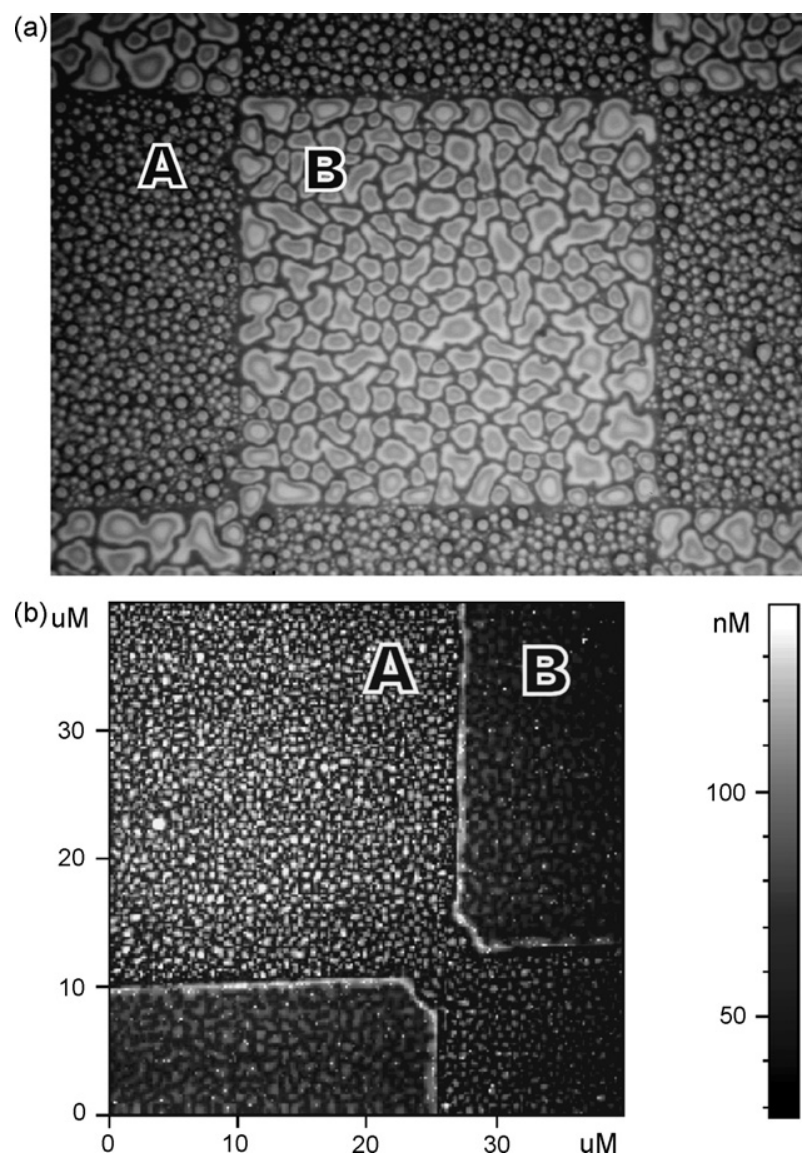

Fig. 9. (a) Optical microscopy image and (b) AFM image of micropatterned ODS (A)-silica (B) surface covered by 10 bilayers of MADQUAT/PAA.

\section{Conclusion}

Experiments described above show that the construction of polyelectrolyte multilayers (as seen up to the fifth bilayer) depends strongly on the functionalization of the substrate. A rather heterogeneous growth with peaks and valleys was gener- ally observed in AFM pictures, but significant variations were seen in the roughness and the peak distribution, due to the initial state of the substrate. Consistently, optical fixed-angle reflectometry revealed large differences in the stepwise polyelectrolyte uptake.

The different morphologies occurring in this investigation were qualitatively understood from the physico-chemical state of the original surface. The principal parameters that influenced the growth were the density and the distribution of charged sites, the density or permeability of the hydrophobic grafted film (using $\mathrm{C}_{3}$ and $\mathrm{C}_{18}$ alkyl chains). Qualitatively the formation of peaks was explained by the incomplete surface coverage in the first step, due to the principle that polyelectrolyte uptake is limited to surface charge neutralisation, if no specific binding takes place. Therefore, the low surface charge density of silica produced a first layer with few molecules, which were isolated generating sites for further growth more likely orthogonal to the surface. We may conclude that the first item in the guideline for controlling the morphology of self-assembled multilayers start by designing an appropriate surface pattern and charge density. Implicitly, it might be the reason why in a number of cases the self-assembled multilayer film construction starts with the deposition of poly(ethylene imine), which is a cationic highly branched polyelectrolyte that develops a strong specific interaction with about any technological material.

Finally the use of a patchwork-like substrate showed (i) that the growth of self-assembled films has been controlled in this investigation by controlling the functionality of the surface and (ii) the possibility to produce complex morphologies in view of specific applications.

\section{Acknowledgements}

We thank Dr J.-M. Suau from Coatex for providing us with the polyelectrolytes and Dr H. Haidara from the Institute of Surface Chemistry and Interface, Mulhouse, France for fruitful discussions about surface modifications. We are grateful to G. Thuillier, PhD student at the FEMTO-ST/LPMO Laboratory, Besançon, France, for his help in the preparation of patterned surfaces. This work was supported by the French-Norvegian Science Foundation (FNS).

\section{References}

[1] G. Decher, J.D. Hong, Makromol. Chem., Macromol. Symp. 46 (1991) 321-327.

[2] P. Bertrand, A. Jonas, R. Legras, Macromol. Rapid Commun. 21 (2000) 319.

[3] P.T. Hammond, Curr. Opin. Colloid Interface Sci. 4 (2000) 430-442.

[4] M. Schönhoff, Curr. Opin. Colloid Interface Sci. 8 (2003) 86-95.

[5] G. Decher, J.B. Schlenoff, Multilayers Thin Films, Wiley-VCH, Weinheim, 2003.

[6] C. Picart, P. Lavalle, P. Hubert, F.J.G. Cuisinier, G. Decher, P. Schaaf, J.-C. Voegel, Langmuir 17 (2001) 7414-7424.

[7] T.J. Halthur, U.M. Elofsson, Langmuir 20 (2004) 1739-1745.

[8] Z. Tang, S.T. Donohoe, J.M. Robinson, P.A. Chiarelli, H. Wang, Polymer 46 (2005) 9043-9052.

[9] G.B. Sukhorukov, E. Donath, H. Lichtenfeld, E. Knippel, M. Knippel, A. Budde, H. Möhwald, Colloids Surf. A 137 (1998) 253-266. 
[10] G.B. Sukhorukov, E. Donath, Polym. Adv. Technol. 9 (1998) 759.

[11] D. Kovacevic, S. van der Burgh, A. de Keizer, M.A. Cohen Stuart, Langmuir 18 (2002) 5607-5612.

[12] C. Buron, Ph.D. Thesis, University of Franche-Comte, 2004.

[13] A. Ulmann, Introduction to Ultrathin Organic Films, Academic Press, Boston, 1991.

[14] K. Mougin, G. Castelein, H. Haidara, Tribol. Lett. 17 (2004) 11-17.

[15] K. Mougin, H. Haidara, G. Castelein, Colloids Surf. A 193 (2001) 231-237.

[16] U. Jonas, C. Krüger, J. Supramol. Chem. 2 (2002) 255-270.

[17] A. Hozumi, H. Sugimura, Y. Yokogawa, T. Kameyama, O. Takai, Colloids Surf. A 182 (2001) 257-261.

[18] C.C. Buron, F. Membrey, C. Filiâtre, A. Foissy, Colloids Surf. A 289 (2006) $163-171$.

[19] T. Roques-Carmes, F. Membrey, C. Filiâtre, A. Foissy, J. Colloid Interface Sci. 245 (2002) 257-266.
[20] T. Roques-Carmes, F. Membrey, M. Kaisheva, C. Filiâtre, A. Foissy, J. Colloid Interface Sci. 299 (2006) 504-512.

[21] C. Picart, J. Mutterer, L. Richert, Y. Luo, G.D. Prestwich, P. Schaaf, J.-C. Voegel, P. Lavalle, Proc. Natl. Acad. Sci. U.S.A. 99 (2002) 12531-12535.

[22] D. Kovacevic, S. van der Burgh, A. de Keizer, M.A. Cohen Stuart, J. Phys. Chem. B 107 (2003) 7998-8002.

[23] F. Boulmedais, V. Ball, P. Schwinte, B. Frisch, P. Schaaf, J.-C. Voegel, Langmuir 19 (2003) 440-445.

[24] P. Lavalle, C. Picart, J. Mutterer, C. Gergely, H. Reiss, J.-C. Voegel, B. Senger, P. Schaaf, J. Phys. Chem. B 108 (2004) 635-648.

[25] Y.M. Lvov, G. Decher, Crystallogr. Rep. 39 (1994) 628-647.

[26] G.J. Fleer, M.A. Cohen Stuart, J.M.H.M. Scheutjens, T. Cosgrove, B. Vincent, Polymers at Interfaces, Chapman and Hall, London, 1993.

[27] L. Wågberg, G. Pettersson, S. Notley, J. Colloid Interface Sci. 274 (2004) 480-488. 